\title{
Isolated Intracranial Myeloid Sarcoma Mimicking Malignant Lymphoma: A Diagnostic Challenge and Literature Reviews
}

\author{
Guixuan $\mathrm{Xu}^{1, *}$ \\ Haijun Zhang ${ }^{1} *$ \\ Weixia Nong ${ }^{2}$ \\ Chunsen $\mathrm{Li}^{1}$ \\ Lian Meng' \\ Chunxia Liu (D) \\ Feng $\mathrm{Li}^{1,3}$
}

'Department of Pathology and Key Laboratories for Xinjiang Endemic and Ethnic Diseases, The First Affiliated Hospital, Shihezi University of Medical, Shihezi, 832002, People's Republic of China; ${ }^{2}$ Department of Hematology, The First Affiliated Hospital of Medical College of Shihezi University, Shihezi 832002, People's Republic of China; ${ }^{3}$ Department of Pathology and Medical Research Center, Beijing Chaoyang Hospital, Capital Medical University, Beijing 100020, People's Republic of China

*These authors contributed equally to this work

Correspondence: Chunxia Liu Department of Pathology and Key Laboratories for Xinjiang Endemic and Ethnic Diseases, The First Affiliated Hospital,Shihezi University of Medical, North 2 Road, Shihezi, Xinjiang 832002 People's Republic of China Email liuliu2239@sina.com

Feng Li

Department of Pathology and Medical Research Center, Beijing Chaoyang Hospital, Capital Medical University, 8 Gongti South Road, Chaoyang District, Beijing 100020, People's Republic of China Email lifeng7855@I26.com
This article was published in the following Dove Press journal: OncoTargets and Therapy

\begin{abstract}
Isolated intracranial myeloid sarcoma (MS) is an unusual variant tumor with few cases reported so far in the medical literature. A 29-year-old woman was admitted to our hospital presenting progressive visual loss in the right eye and weight loss $(20 \mathrm{~kg})$ without a previous history of hematological disease (HD). Radiologic evaluation showed the evidence of intracranial mass. Histologically, the resected tumor was composed of a uniform population of primitive cells and primarily misdiagnosed as a T-cell non-Hodgkin's lymphoma (NHL). Chemotherapy with cyclophosphamide, doxorubicin, vinblastine, and prednisone (CHOP) was ineffective. A biopsy and histopathological evaluation were repeated, and immunohistochemical staining revealed the positivity of immature cells to an extensive panel of myeloid markers. These findings were consistent with a diagnosis of MS and bone marrow infiltration. Literature reviews of previous cases were also undertaken.
\end{abstract}

Keywords: myeloid sarcoma, isolated, intracranial, non-Hodgkin's lymphoma, misdiagnosis

\section{Introduction}

Myeloid sarcoma (MS), also known as granulocytic sarcoma, is a locally invasive tumor mass of extramedullary tissues consisting of myeloid blasts with or without maturation. It is a rare and peculiar disease that can occur in any part of the body, with intracranial MS being extremely rare. ${ }^{1,2}$ MS diagnosis is challenging, particularly without a known history of any hematological disease (HD). Thus, isolated MS is easily misdiagnosed. ${ }^{3}$ According to a population-based study, the misdiagnosis rate of MS can be as high as $40 \%{ }^{2} \mathrm{MS}$ is one of the most likely to be misdiagnosed as malignant lymphoma. ${ }^{2,4,5}$ Misdiagnosis is often corrected after bone marrow and/or blood tests for suspected acute leukemia. ${ }^{5}$ We found an unusual and challenging case of isolated intracranial MS with myelofibrosis that was misdiagnosed as T-cell non-Hodgkin's lymphoma (NHL) and reviewed literature to raise awareness on this disease.

\section{Case Presentation}

In May 2018, a 29-year-old woman who was healthy until she was admitted to our hospital for a one-month history of progressive visual loss in the right eye and unexplained weight loss of $20 \mathrm{~kg}$ within one year. The physical evaluation showed that the patient had signs of anemia but no fever and superficial lymphadenopathy. Complete blood count was normal except for a red blood cell count of $2.82 \times 10^{9} / \mathrm{L}$ 
and hemoglobin levels of $85 \mathrm{~g} / \mathrm{L}$. Computed tomography (CT) of the brain showed saddle area-occupying lesions (Figure 1A). The patient immediately underwent an endoscopic sellar region tumor resection.

The mass was a small pile of greyish-yellow, dark red broken tissue with a volume of approximately $2.0 \times 1.5 \times$ $0.5 \mathrm{~cm}$. Microscopically, the tumor was composed of diffuse infiltration of primitive and small blue cells (Figure 2A). A subset of tumor cells was eosinophilic with large round or oval nuclei, fine chromatin, and small nucleoli (Figure 2B). In certain areas, heterogeneous cells were characterized by diffuse infiltration of tissues with large nuclei, high nucleocytoplasmic (N:C) ratio, irregular nuclear contours, and small nucleoli (Figure 2C). At high magnification, the chromatin was fine, and the nucleoli could be noted (Figure 2D). The tumor cells were positive for LCA, CD4 (Figure 3A) and CD43; scattered positive for CD3 (Figure 3B) and CD8; but negative for AE1/3, EMA, S-100, CD10, CD20, and CD79a. Approximately $60 \%$ of tumor cells were positive for $\mathrm{Ki}$ 67, indicating a high proliferation index (Figure 3C). Morphological examination of bone marrow cells documented a decrease in myeloproliferative disorder with $6 \%$ of the
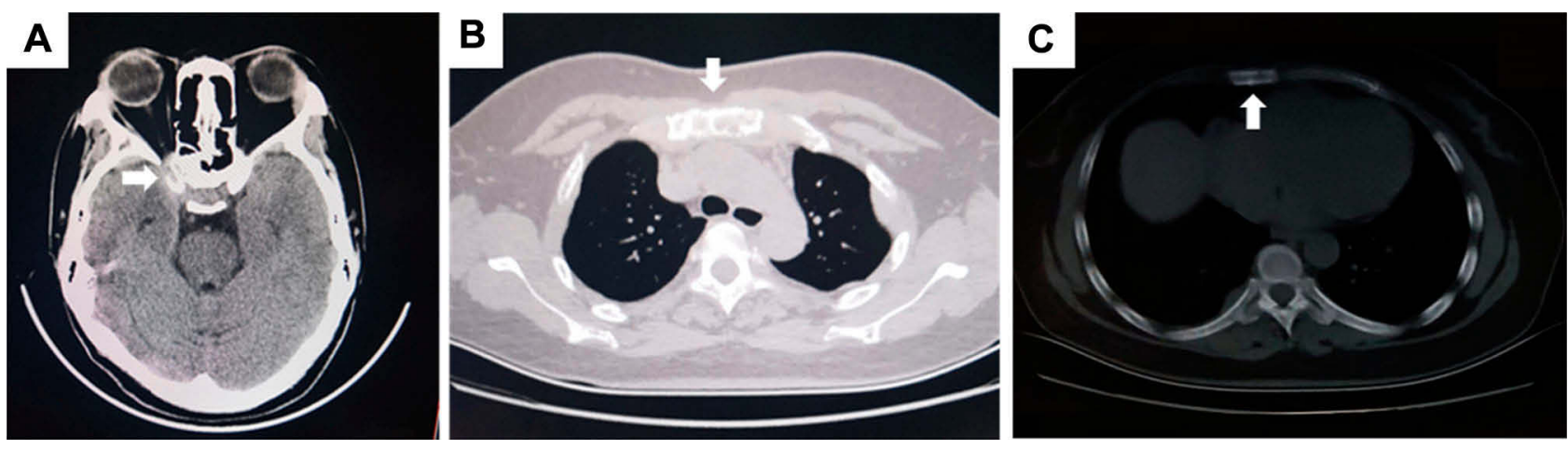

Figure I Computed tomography (CT) scan findings. (A) Preoperative CT showed an irregular soft tissue density mass in the saddle area, and the boundary with surrounding tissues was not clear. (B and C) Chest CT showed abnormal density of the thoracic spine and discontinuity of the sternal bone.
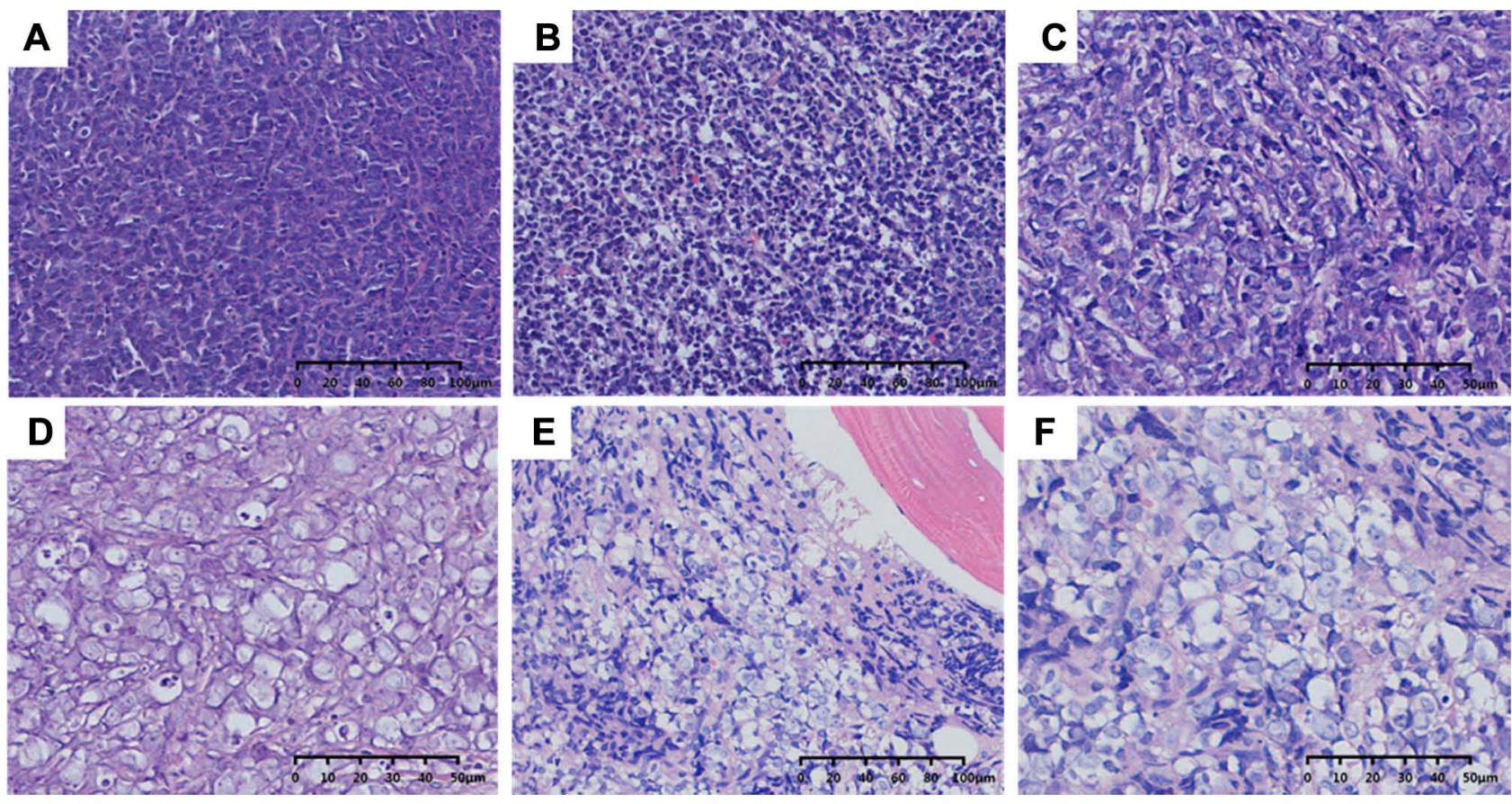

Figure 2 Histopathological features of MS. (A) Diffuse infiltration of tumor cells and round-shaped malignant lymphoid cells with less cytoplasm (H\&E; $\times 200)$. (B) A small amount of mature or naive eosinophils and abundant interstitial blood vessels can be found between neoplastic cells (H\&E; $\times 200)$. (C) High N:C ratio, small nucleoli, and numerous mitotic figures (H\&E; $\times 400)$. (E) The neoplasm consists of blasts with round-oval nuclei with finely dispersed chromatin (H\&E; $\times 200)$. (D and F) The neoplasm consists of blasts with round-oval nuclei with finely dispersed chromatin and distinct nucleoli. Various numbers of lymphocyte infiltrations are present (H\&E; $\times 400)$. 

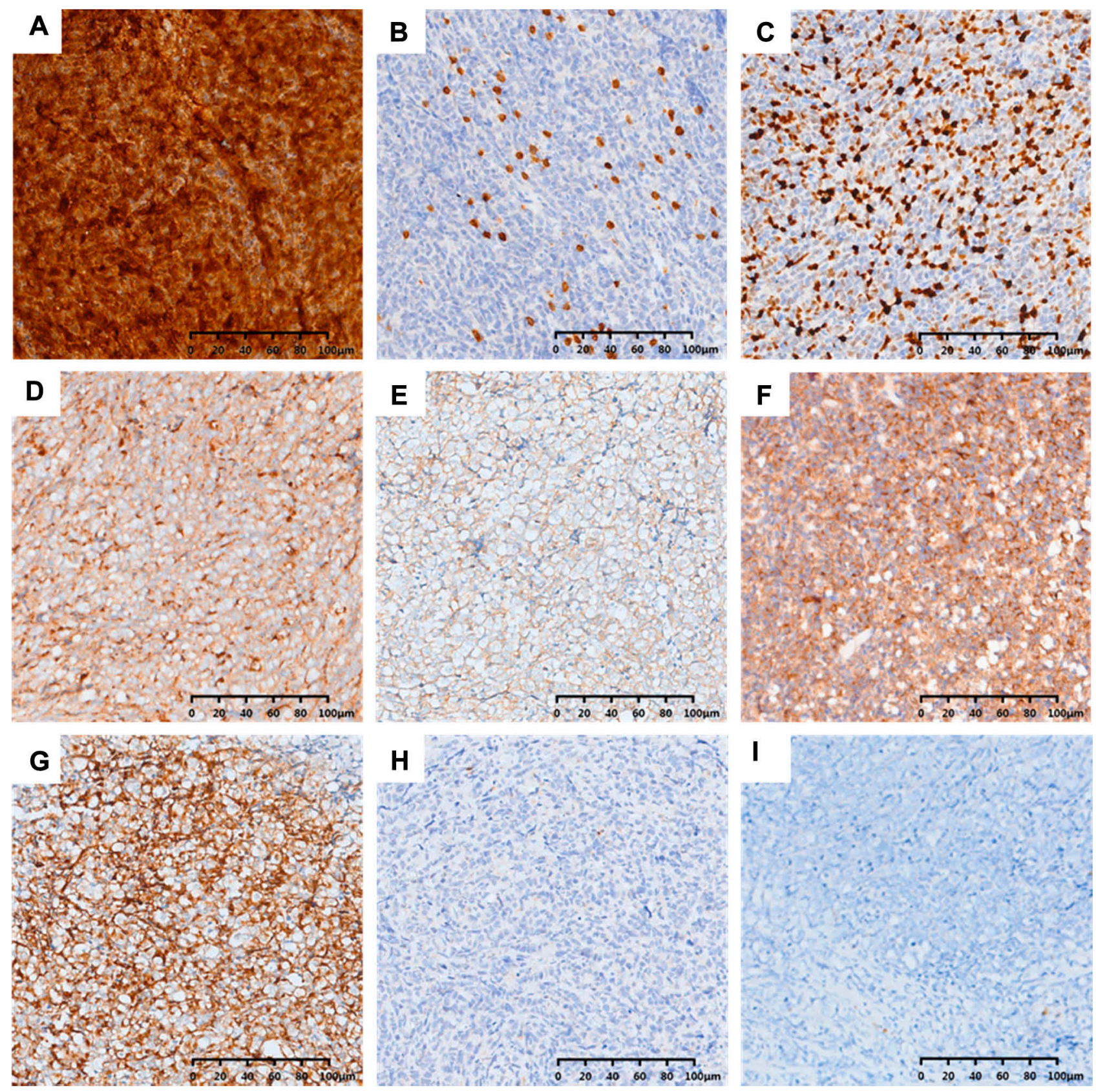

Figure 3 Immunohistochemical findings (original magnification $\times 200$ ). (A)Infiltrative cells are CD4 positive. (B) CD3 diffuse positivity. (C) Ki-67 proliferation index is $60 \%$. Neoplastic cells positive for (D) CD68, (E) CDI I7, (F) CD99, and (G) CD34 and negative for (H) MPO and (I) TdT.

primitive cells, without evidence of neoplastic cells (Figure 4A). Subsequently, further cytogenetic examinations were recommended, but the bone marrow is dry pumped in vain. On the basis of these results, the initial diagnosis was considered as T-cell NHL. Considering that the patient had no contraindications for chemotherapy, CHOP regimen chemotherapy was initiated in 1 month following resection.

With regard to the clinical conditions of the patient, no improvement was noted on the blindness in the right eye, refractory anemia (minimum hemoglobin levels of $43 \mathrm{~g} / \mathrm{L}$ ), and sternal tenderness. 8 months after tumor resection, morphological evaluation of bone marrow cells documented that immature/primitive cells accounted for $81.5 \%$, and the proliferation of granulocytic, erythrocytic and megakaryocytic cells were inhibited (Figure 4B). CT showed diffuse abnormal bone density in the limbs, ribs, sternum (Figures 1B and C), spine, and pelvis. Successful bone marrow puncture displayed a population of medium-sized myeloid primitive cells associated with fibrosis and scattered eosinophils (Figures 2E and F). However, karyotype analyses failed. 

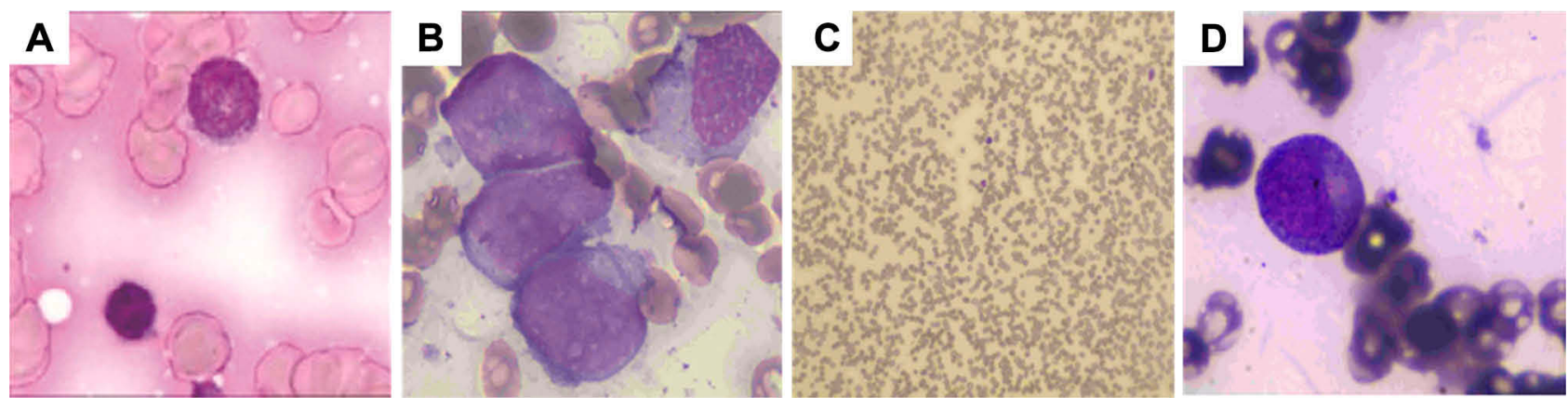

Figure 4 Bone marrow cell morphology. (A) Cells were medium, round, or elliptical; the nucleus is round or oval, and the chromatin is granular. (B) Tumor cells were round; certain cells were slightly irregular; the chromatin was loose; the nucleolus was obvious, and the cytoplasm was less. (C and $\mathbf{D})$ Occasionally visible primitive cells.

The previous diagnosis was reviewed, and additional immunohistochemistry staining showed positive for CD68 (Figure 3D), CD117 (Figure 3E), CD99 (Figure 3F), CD1a and CD34 (Figure 3G), but negative for MPO (Figure 3H) and TdT (Figure 3I). The final diagnosis of MS was confirmed after the patient's pathological files were sent to another hospital for consultation. At present, the chemotherapy regimen was adjusted to high-dose cytosine arabinoside and the patient has postoperatively received consolidation chemotherapy for 4 cycles $\left(1 \mathrm{~g} / \mathrm{m}^{2}\right.$ cytarabine per half a day for 3 days). Bone marrow biopsies and radiological examination were performed to evaluate patient's post-treatment results. Bone marrow cytology showed reduced nucleated cell proliferation and occasional primitive cells (Figure 4C). Detection of minimal residual disease (MRD) (through flow cytometry) revealed no abnormal primitive (myeloid/NK precursor) cells (Figure $\underline{\mathrm{S} 1 \mathrm{~A})}$. Chest radiograph showed normal sternum and thoracic vertebra. The ribs, clavicle and scapula still have diffuse bone density unevenness. After 3 months, the latest bone marrow cytology occasionally showed primitive cells (Figure 4D), and no obvious myeloid primitive cells were found in MRD (below the lower detection limit: $10^{4}$ ) (Figure S1B). The patient's condition is stable, and follow up will be continued.

\section{Discussion}

Burns first described MS in $1811,{ }^{6}$ commonly known as chloroma $^{7}$ and granulocytic sarcoma. ${ }^{8}$ In 1893, Dock established its association with leukemia. MS may occur previously, simultaneously, or secondary to AML, chronic myeloid leukemia, myeloproliferative disorder, myelodysplastic syndrome, and essential thrombocythemia. ${ }^{2,9}$ The 2016 revised WHO classification continued to classify MS as a unique clinical manifestation of AML subtype and pointed out that MS can occur independently of the peripheral blood and bone marrow. MS extramedullary infiltration frequently affects the bone, eyelids, lymph nodes, and skin. ${ }^{1,2}$ The involvement of the central nervous system is only $0.4 \%,{ }^{4}$ while the cases of intracranial MS are fewer. Literature search only shows eight similar reports (isolated intracranial MS) from January 2000 to June 2019 (Table 1). ${ }^{10-17}$

MS is generally diagnosed by a comprehensive analysis of clinical and imaging features, tissue biopsy, immunohistochemistry and molecular analyses. MS nodules or masses, which are characterized using radiologic evaluation, are denser than the brain parenchyma or are equivalent to muscles on CT scans. Enhanced scans show moderate-to-severe intensification. ${ }^{9,18}$ Given the lack of understanding and attention to this disease, clinical and pathological diagnosis is challenging. The freshly cut surface of the tumors generally appears green due to peroxidase oxidation, whereas approximately $30 \%$ of the surface do not exhibit this color. ${ }^{7,8}$ When the tumor displays a greyish red or greyish yellow color, pathologists tend to ignore the possibility of MS. Morphologically, MS lesions infiltrate into granulocytes, monocytes, or mononuclear cells. The tumor cells are diffusely distributed, uniform in shape and small-to-medium size, and therefore be confused with T-cell lymphoma, diffuse large B-cell lymphoma, or poorly differentiated carcinoma in adults, particularly under the hematoxylin-eosin (H\&E) stain. MS is often misdiagnosed as NHL (Table 2). ${ }^{4,5,10,19}$ Another feature that supports MS diagnosis is the presence of eosinophils in tumor cells. However, eosinophils are not specific and often unnoticed. Unfortunately, we ignored this feature during the initial diagnosis.

To some extent, immunohistochemical staining allows making an appropriate diagnosis. ${ }^{20}$ Immunohistochemical 


\begin{tabular}{|c|c|c|c|c|c|c|c|c|c|}
\hline 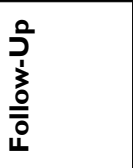 & 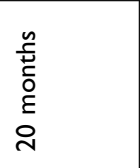 & 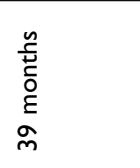 & $\begin{array}{l}\stackrel{n}{\mathbb{N}} \\
\stackrel{x}{\lambda}\end{array}$ & 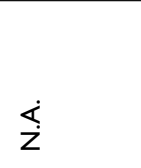 & 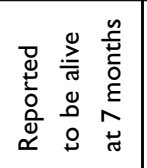 & 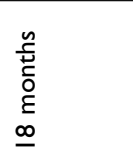 & 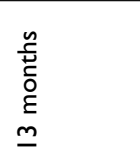 & $\overleftarrow{z}$ & $\stackrel{0}{\stackrel{2}{\alpha}}$ \\
\hline 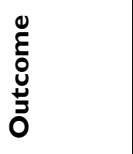 & Ư & Ư & Ư & $\begin{array}{l}\text { 䓌 } \\
\text { D̃ }\end{array}$ & 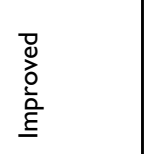 & 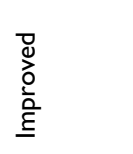 & Ư & $\begin{array}{l}\text { 㔛 } \\
\text { D̃ }\end{array}$ & 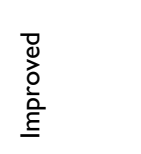 \\
\hline 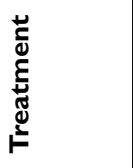 & 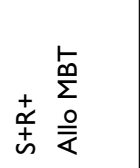 & $\begin{array}{l}\stackrel{q}{+} \\
\stackrel{+}{+} \\
\pm\end{array}$ & 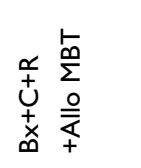 & 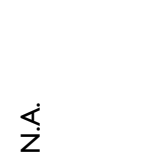 & $\begin{array}{l}U \\
\pm \\
+ \\
+ \\
\times \\
0\end{array}$ & $\begin{array}{l}U \\
+ \\
\times \\
\infty\end{array}$ & $\begin{array}{l}\text { U } \\
\text { W }\end{array}$ & $n$ & $\begin{array}{l}\text { U } \\
+\end{array}$ \\
\hline 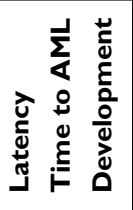 & 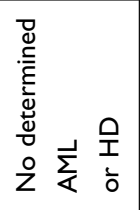 & 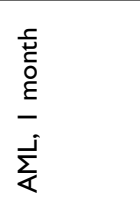 & 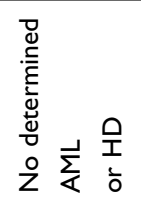 & 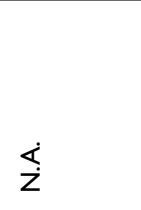 & 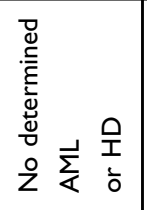 & 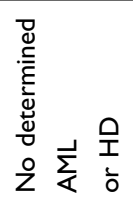 & 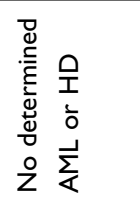 & 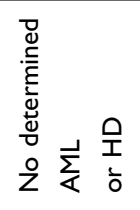 & 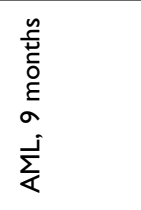 \\
\hline 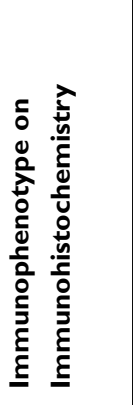 & ¿ & 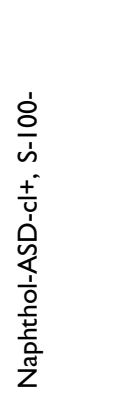 & 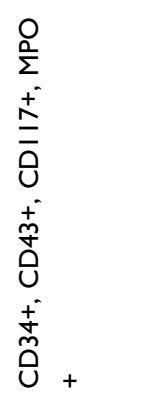 & $\begin{array}{l}+ \\
0 \\
\Sigma \\
\Sigma\end{array}$ & 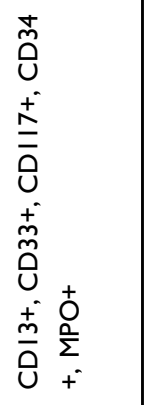 & 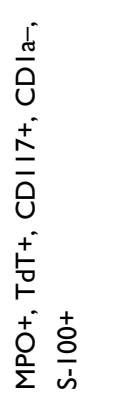 & 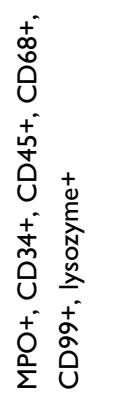 & 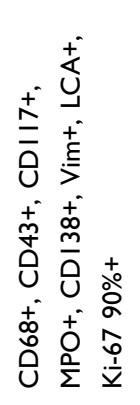 & 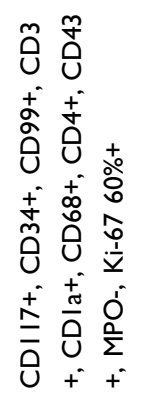 \\
\hline 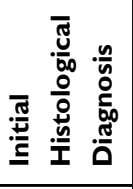 & $\overrightarrow{\underline{T}}$ & zo & $\stackrel{\circ}{z}$ & $\stackrel{0}{z}$ & ¿o & ¿o & ㅇ & 으 & 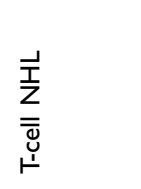 \\
\hline $\begin{array}{l}\text { है } \\
\dot{0} \\
\text { है } \\
\text { है }\end{array}$ & 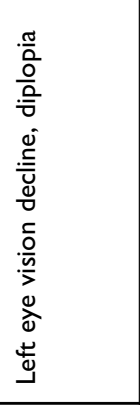 & 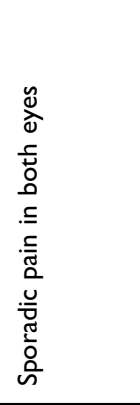 & 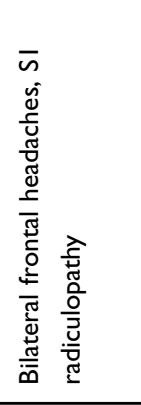 & 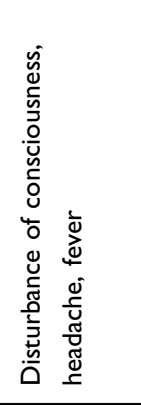 & 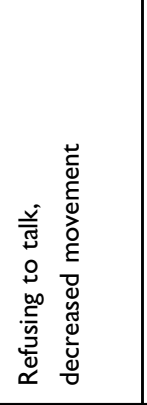 & $\begin{array}{l}\frac{0}{\tilde{J}} \\
\frac{\pi}{\pi} \\
\frac{\mathbb{J}}{I}\end{array}$ & 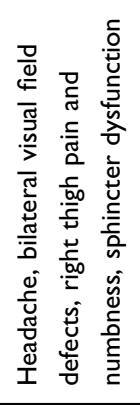 & 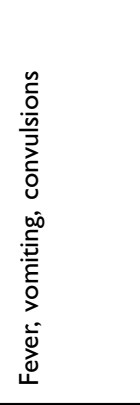 & 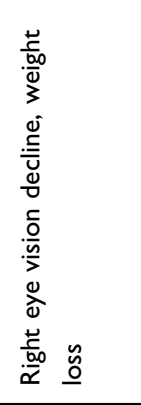 \\
\hline 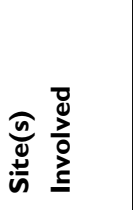 & $\begin{array}{l}\stackrel{x}{\bar{E}} \\
\stackrel{x}{\underline{e}}\end{array}$ & 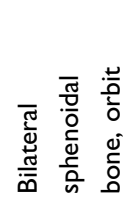 & 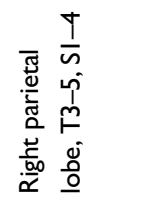 & 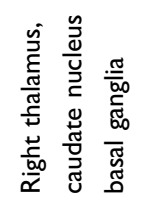 & 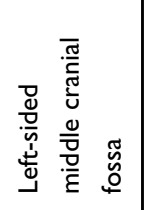 & 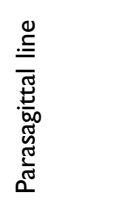 & 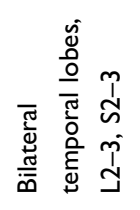 & 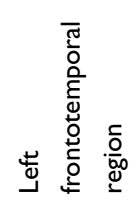 & 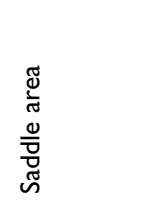 \\
\hline ڤ్ & $\Sigma$ & $\Sigma$ & 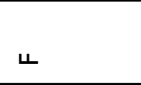 & $\Sigma$ & 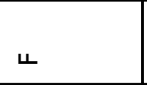 & $\Sigma$ & $\Sigma$ & \llcorner & ч \\
\hline 范 & $\stackrel{\stackrel{n}{m}}{n}$ & $m$ & $\stackrel{\llcorner}{m}$ & సి & $\bar{\gamma}$ & ה & $\hat{\lambda}$ & $\stackrel{\text { นn }}{0}$ & సి \\
\hline $\begin{array}{l}\stackrel{y}{y} \\
\text { ũ }\end{array}$ & $\stackrel{ }{-}$ & $\bar{\sim}$ & $\frac{N}{m}$ & $\stackrel{m}{t}$ & $\frac{t}{\omega n}$ & - & $\bar{\lambda}$ & $\AA_{\infty}$ & 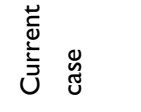 \\
\hline
\end{tabular}


Table 2. Misdiagnosed Myeloid Sarcoma Cases

\begin{tabular}{|c|c|c|c|c|c|c|c|c|}
\hline Case & $\begin{array}{l}\text { Age, } \\
\text { years }\end{array}$ & Sex & $\begin{array}{l}\text { Site(s) } \\
\text { Involved }\end{array}$ & Symptoms & $\begin{array}{l}\text { Initial } \\
\text { Histological } \\
\text { Diagnosis }\end{array}$ & $\begin{array}{l}\text { Initial } \\
\text { Immunohistochemistry }\end{array}$ & $\begin{array}{l}\text { Initial } \\
\text { HD } \\
\text { Diagnosis }\end{array}$ & $\begin{array}{l}\text { Correct Diagnosis Method } \\
\text { and Result }\end{array}$ \\
\hline $1^{4}$ & 47 & M & $\begin{array}{l}\text { Skin of the } \\
\text { nasolabial fold, } \\
\text { testis }\end{array}$ & N.A. & $M L$ & N.A. & NO & N.A. \\
\hline $2^{4}$ & 50 & M & Supraclavicular & N.A. & $M L$ & N.A. & NO & N.A. \\
\hline $3^{19}$ & 48 & M & Left testicle & $\begin{array}{l}\text { Left } \\
\text { testicular } \\
\text { swelling }\end{array}$ & $M L$ & N.A. & N.A. & N.A. \\
\hline $4^{10}$ & 35 & M & Meninx & $\begin{array}{l}\text { Left eye } \\
\text { vision } \\
\text { decline }\end{array}$ & $\mathrm{NHL}$ & N.A. & N.A. & $\begin{array}{l}\text { Chloroacetate esterase stain+, } \\
\text { myelomonocytic markers+, } \\
\text { leukocyte common antigen+, } \\
\text { B-/T-cell-specific antigens- }\end{array}$ \\
\hline $5^{5}$ & 64 & M & Left testis & $\begin{array}{l}\text { Swelling of } \\
\text { his left testis }\end{array}$ & $\mathrm{NHL}$ & MPO+, lysozyme+ & NO & $\begin{array}{l}\text { AML was suspected by bone } \\
\text { marrow and blood } \\
\text { examinations }\end{array}$ \\
\hline $6^{19}$ & 71 & M & Left testicle & $\begin{array}{l}\text { Left } \\
\text { testiculai } \\
\text { swelling }\end{array}$ & Plasmacytoma & N.A. & N.A. & N.A. \\
\hline $7^{4}$ & 49 & $\mathrm{~F}$ & Cervical & N.A. & $\begin{array}{l}\text { Lymphoblast } \\
\text { proliferation }\end{array}$ & N.A. & N.A. & N.A. \\
\hline $\begin{array}{l}\text { Current } \\
\text { case }\end{array}$ & 29 & $\mathrm{~F}$ & Saddle area & $\begin{array}{l}\text { Right eye } \\
\text { vision } \\
\text { decline, } \\
\text { weight loss }\end{array}$ & T-cell NHL & $\begin{array}{l}\mathrm{LCA}+, \mathrm{CD} 3+, \mathrm{CD} 4+ \\
\mathrm{CD} 43+, \mathrm{CD} 20-, \mathrm{CD} 79 \mathrm{a}- \\
\mathrm{Ki}-6760 \%+\end{array}$ & NO & $\begin{array}{l}\text { Re-biopsy, further IHC: } \\
\text { myelomonocytic markers+ }\end{array}$ \\
\hline
\end{tabular}

Abbreviations: M, male; F, female; AML, acute myeloid leukemia; HD, hematological disease; NHL, non-Hodgkin's lymphoma; ML, malignant lymphoma; N.A., not applicable.

markers are complex, and incorrect analysis can lead to misdiagnosis. In our case, initial immunohistochemical staining has demonstrated positive for $\mathrm{T}$ cell antibodies (CD3, CD4, CD8, and CD43) but negative for B-cell antibodies (CD20 and CD79a). We neglected that CD43 is not only a T-cell marker but is also expressed in almost all myeloid cell sarcomas. ${ }^{21}$ Moreover, a small number of MS can express T-cell antigens. Two studies have reported that MS can express CD4 $(1.1 \%)^{2}$ and CD3 $(20.7 \%){ }^{22}$ The common positive cell surface antigens of MS include MPO, lysozyme, CD68, CD117, CD99, CD34, and TdT. In our supplemental immunohistochemistry, CD117, CD34, CD99, CD1a, and CD68 are positive, further confirming the establishment of MS diagnosis. CD117 and MPO positivity often indicate that tumor cells have myeloid differentiation. MPO is a specific marker of myeloid cells, has high sensitivity and specificity and has been considered as a marker of MS in recent years. ${ }^{23}$ Keisuke Kawamoto analyzed 131 cases of MS and reported a $63.2 \%$ positive expression rate of $\mathrm{MPO},{ }^{22}$ demonstrating that not all MS express MPO. When MPO is negative, the expression of paraffin sections CD41 and CD61 contributes to the diagnosis. Thus, tissue biopsy and immunohistochemistry are particularly important for accurate diagnosis of MS when clinical features are inadequate.

A complete diagnosis of MS should include risk stratification of the disease and assessment of targeted therapy. Therefore, molecular analyses associated with MS is essential, which may remarkably improve the outcome and prognosis of patients. ${ }^{9,24}$ The chromosomal translocations t $(8 ; 21)$ (q22; q22) are the commonest cytogenetic mutations, producing an AML1-ETO fusion gene at the molecular level. ${ }^{25}$

Given the lack of a large randomized controlled trial of MS, the treatment strategy of MS remains to be 
a controversy. ${ }^{25}$ Currently, systemic chemotherapy is the main treatment for MS. When the isolated MS is diagnosed, systemic chemotherapy should be initiated, a treatment regimen of systemic chemotherapy regimen for AML-like is recommended. ${ }^{9,20}$ Some studies have found that chemotherapy regimens containing cytarabine are an essential part of MS systemic chemotherapy. ${ }^{20}$ Other treatments include local radiotherapy, allogeneic bone marrow transplantation, molecular targeting and immunotherapy. The latest singleinstitution experience points out that after the first induction of remission, allogeneic hematopoietic stem cell transplantation (HSCT) is the effective modality to achieve long-term remission. ${ }^{26}$ Highly targeted therapies produce good results that offer opportunities for MS patients; for example, humanized anti-CD33 monoclonal antibodies are used for targeted therapy in patients with CD33-positive AML-related MS. ${ }^{27}$ And targeted therapy with tyrosine kinase inhibitors in MS patients associated with BCR-ABL1, FLT3-ITD and FIP1L1PDGFRA mutations. ${ }^{28}$ Kanate et $\mathrm{al}^{29}$ reported that orally administered $400 \mathrm{mg}$ of single-agent venetoclax induces a remarkable result for refractory MS. A new molecule CPI613 (6,8-bis [benzylthio] octanoic acid) with cytarabine and mitoxantrone hydrochloride treatment has been entered into the pilot phase II trial. This study expects to be completed in February 2022 and is a promising approach for refractory/ relapsed AML or MS. ${ }^{30}$

\section{Conclusion}

The diagnosis of intracranial MS pathologies in patients without HD is challenging. According to our case and literature reviews, local surgical decompression combined with high dose cytarabine is effective in controlling tumor masses, including progressive neurological deterioration. Both improvements in long-term survival and remission of isolated MS or MS with AML are still dependent on systemic chemotherapy and HSCT. In addition, subtargeted therapy has potential application in emerging individualized medicine.

\section{Consent to Publish}

Written informed consent was obtained from the patient for publication of this case report and the accompanying images. The images did not contain the patient records and information. This study was approved by the Clinical Research Ethics board of the First Affiliated Hospital, Shihezi University School of Medicine.

\section{Acknowledgment}

This study was supported by the National Natural Science Foundation of China (Nos 81660441 and 81960485) and Science and Technology Development Project of Xinjiang Production and Construction Corps (2018AB033).

\section{Disclosure}

The authors declare no conflicts of interest for this article.

\section{References}

1. Imrie KR, Kovacs MJ, Selby D, et al. Isolated chloroma: the effect of early antileukemic therapy. Ann Intern Med. 1995;123(5):351-353. doi:10.7326/0003-4819-123-5-199509010-00005

2. Pileri SA, Ascani S, Cox MC, et al. Myeloid sarcoma: clinico-pathologic, phenotypic and cytogenetic analysis of 92 adult patients. Leukemia. 2007;21(2):340-350. doi:10.1038/sj.leu.2404491

3. Meis JM, Butler JJ, Osborne BM, Manning JT. Granulocytic sarcoma in nonleukemic patients. Cancer. 1986;58(12):2697-2709. doi:10.10 02/1097-0142(19861215)58:12<2697::AID-CNCR2820581225>3.0. $\mathrm{CO} ; 2-\mathrm{R}$

4. Neiman RS, Barcos M, Berard C, Bonner H, Bennett JM. Granulocytic sarcoma: A clinicopathologic study of 61 biopsied cases. Cancer. 1981;48 (6):1426-1437. doi:10.1002/1097-0142(19810915)48:6<1426::AID-CN CR2820480626>3.0.CO;2-G

5. Yamauchi K, Yasuda M. Comparison in treatments of nonleukemic granulocytic sarcoma: report of two cases and a review of 72 cases in the literature. Cancer. 2002;94(6):1739-1746. doi:10.1002/cncr.10399

6. Burns A. Observations on the surgical anatomy of the head and neck. Medico-Chirurgical J Rev. 1816;1(3):234-250.

7. King A. A case of chloroma. Monthly J Med. 1853;8(44):97-104.

8. Rappaport H. Tumors of the hematopoietic, system section iii, fascicle 8. Armed Forces Inst Pathol. 1966;241-243.

9. Almond LM, Charalampakis M, Ford SJ, Gourevitch D, Desai A. Myeloid sarcoma: presentation, diagnosis, and treatment. Clin Lymphoma Myeloma Leuk. 2017;17(5):263-267. doi:10.1016/j.clm1.2017.02.027

10. Binder C, Tiemann M, Haase D, Humpe A, Kneba M. Isolated meningeal chloroma (granulocytic sarcoma) a case report and review of the literature. Ann Hematol. 2000;79(8):459-462. doi:10.1007/ s002770000165

11. Ohta K, Kondoh T, Yasuo K, Kohsaka Y, Kohmura E. Primary granulocytic sarcoma in the sphenoidal bone and orbit. Childs Nervous System. 2003;19(9):674-679. doi:10.1007/s00381-003-0797-y

12. Widhalm G, Dietrich W, Müllauer L, et al. Myeloid sarcoma with multiple lesions of the central nervous system in a patient without leukemia. J Neurosurg. 2006;105(6):916-919. doi:10.3171/jns.2006.105.6.916

13. Passarin MG, Vattemi E, Musso AM, et al. Intracranial granulocytic sarcoma after chemotherapy for pineal germinoma and testicular cancer. J Clin Oncol. 2008;26(27):4507-4509. doi:10.1200/JCO.2008.17.0787

14. Grier DD, Al-Quran SZ, Gray B, Li Y, Braylan R. Intracranial myeloid sarcoma. Br J Haematol. 2008;142(5):681. doi:10.1111/ j.1365-2141.2008.07169.x

15. Gunaldi M, Kara IO, Duman BB, Ercolak V. Primary intracerebral myeloid sarcoma. Onkologie. 2012;35(11):694-697. doi:10.1159/ 000343953

16. Yang C, Liu Y, Li G, Bai J, Qian J, Xu Y. Multifocal myeloid sarcoma in the central nervous system without leukemia. Clin Neurol Neurosurg. 2014;120:99-102. doi:10.1016/j.clineuro.2014.02. 020

17. Zhu J, Thapa S, Wang X, Jiang C, Qu Y, Wen Z. Isolated intracranial myeloid sarcoma at age 6 months with metastases. Clin Neuroradiol. 2019;29(4):791-795. doi:10.1007/s00062-019-00779-z 
18. Gustavo C, Zuzan C. Intracranial CNS manifestations of myeloid sarcoma in patients with acute myeloid leukemia: review of the literature and three case reports from the author's institution. J Clin Med. 2015;4(5):1102-1112. doi:10.3390/jcm4051102

19. Ferry J, Srigley JR, Young RH. Granulocytic sarcoma of the testis: a report of two cases of a neoplasm prone to misinterpretation. Mod Pathol. 1997;10(4):320-325.

20. Avni B, Koren-Michowitz M. Myeloid sarcoma: current approach and therapeutic options. Ther Adv Hematol. 2011;2(5):309-316. doi:10.1177/2040620711410774

21. Traweek ST, Arber DA, Rappaport H, Brynes RK. Extramedullary myeloid cell tumors. An immunohistochemical and morphologic study of 28 cases. Am J Surg Pathol. 1993;17(10):1011-1019. doi:10.1097/00000478-199310000-00006

22. Kawamoto K, Miyoshi H, Yoshida N, Takizawa J, Sone H, Ohshima K. Clinicopathological, cytogenetic, and prognostic analysis of 131 myeloid sarcoma patients. Am J Surg Pathol. 2016;40 (11):1473. doi:10.1097/PAS.0000000000000727

23. Mourad K, Al H. The value of CD34, myeloperoxidase and chloroacetate esterase (Leder) stain in the diagnosis of granulocytic sarcoma. Ann Saudi Med. 2001;21(5-6):287-291. doi:10.5144/0256-4947.2001.287

24. Claerhout H, Van Aelst S, Melis C, et al. Clinicopathological characteristics of de novo and secondary myeloid sarcoma: A monocentric retrospective study. Eur J Haematol. 2018;100 (6):603-612. doi:10.1111/ejh.13056
25. Bakst RL, Tallman MS, Dan D, Yahalom J. How I treat extramedullary acute myeloid leukemia. Blood. 2011;118(14):3785-3793. doi:10.1182/blood-2011-04-347229

26. Kaur V, Swami A, Alapat D, et al. Clinical characteristics, molecular profile and outcomes of myeloid sarcoma: a single institution experience over 13 years. Hematology. 2018;23(1):17-24. doi:10.1080/ 10245332.2017.1333275

27. Piccaluga PP, Martinelli G, Rondoni M, et al. Gemtuzumab ozogamicin for relapsed and refractory acute myeloid leukemia and myeloid sarcomas. Leuk Lymphoma. 2004;45(9):1791-1795. doi:10.1080/ 1042819042000219485

28. Vedy D, Muehlematter D, Rausch T, Stalder M, Jotterand M, Spertini O. Acute myeloid leukemia with myeloid sarcoma and eosinophilia: prolonged remission and molecular response to Imatinib. J Clin Oncol. 2010;28(3):e33-e35. doi:10.1200/JCO.2009.23.6976

29. Kanate A, Vos J, Chargualaf M. Venetoclax for refractory myeloid sarcoma. J Oncol Pract. 2019;15(7):413-415. doi:10.1200/JOP.18.00753

30. Wake Forest University Health Sciences. CPI-613, cytarabine, and mitoxantrone hydrochloride in treating patients with relapsed or refractory acute myeloid leukemia or granulocytic sarcoma. Available from: https:/clinicaltrials.gov/ct2/show/NCT02484391. NLM identifier: NCT02484391. Accessed April 20, 2020.

\section{Publish your work in this journal}

OncoTargets and Therapy is an international, peer-reviewed, open access journal focusing on the pathological basis of all cancers, potential targets for therapy and treatment protocols employed to improve the management of cancer patients. The journal also focuses on the impact of management programs and new therapeutic agents and protocols on patient perspectives such as quality of life, adherence and satisfaction. The manuscript management system is completely online and includes a very quick and fair peer-review system, which is all easy to use. Visit http://www.dovepress.com/ testimonials.php to read real quotes from published authors. 